\title{
PENGARUH RELAKSASI NAFAS DALAM TERHADAP PENURUNAN INTENSITAS NYERI HAID PADA REMAJA PUTRI DI MAN INSAN CENDEKIA HALMAHERA BARAT
}

\author{
THE EFFECT OF RELAXATION IN BREATH AGAINST REDUCTION \\ IN MENSTRUAL PAIN INTENSITY IN YOUNG WOMEN \\ IN MAN INSAN SCHOLAR WEST HALMAHERA
}

\author{
Nurkila Suaib \\ Program Studi Diploma IV Kebidanan, Politeknik Kesehatan Kementerian Kesehatan Ternate \\ ${ }^{2}$ Program Studi Kesehatan Masyarakat STIK Bina Husada Palembang, Indonesia
}

Korespondensi:

\begin{abstract}
Dysmenorrhea is the most common complaint that causes young women to go to the doctor for consultation and treatment (Winknjosastro, 2007). The prevalence of dysmenorrhea in several studies shows a fairly high frequency. In a WHO systemic review, the average incidence of dysmenorrhea in young women was between 16.8-81\%. Research Objectives: To Know The Effect Of Giving Relaxation In Breath Against Decreasing Intensity of Menstrual Pain in Young Women in MAN Insane Scholar West Halmahera. Research Methods: Experiments with the design of one group pre-post test design is to reveal the causal relationship by involving a group of subjects that were observed before the intervention, then observed again after intervention. The sampling technique is a total sampling. The instrument used was a questionnaire while the data analysis technique was multifarious, with a large sample of 27 people. Results: there is a significant relationship between the relaxation of a Deep Breath on the reduction in Menstrual Pain Intensity in Ramaja Putri Schoolgirl in MAN Insan Scholar West Halmahera that is by looking at the statistical calculation results $P$-value $=0.0001$ which means $\alpha<0.05$. Conclusion: Breath relaxation techniques in providing a significant influence on the intensity of menstrual pain in Young Women in MAN Insan Scholar West Halmahera.
\end{abstract}

Keywords $\quad$ : Intensity of Menstrual Pain, Deep Breath Relaxation Techniques

\begin{abstract}
ABSTRAK
Dismenore adalah keluhan yang paling sering menyebabkan wanita muda pergi ke dokter untuk konsultasi dan mendapatkan pengobatan (Winknjosastro, 2007). Prevalensi dismenore dalam beberapa penelitian menunjukkan frekuensi yang cukup tinggi. Dalam suatu systemic review WHO, rata-rata insidensi terjadinya dismenore pada wanita muda antara $16,8-81 \%$. Tujuan penelitian ini mengetahui Pengaruh Pemberian Relaksasi Nafas Dalam Terhadap Penurunan Intensitas Nyeri Haid Pada Remaja Putri Di MAN Insan Cendekia Halmahera Barat. Metode Penelitian yang digunakan Praeksperimen dengan rancangan one group pra-post test eisign adalah mengungkapkan hubungan sebab akibat dengan cara melibatkan suatu kelompok subjek
\end{abstract}


yang diobservasi sebelum dilakukan intevensi, kemudian diobservasi lagi setelah diintervensi. Teknik pegambilan Sampel adalah Total Sampling. Instrumen yang digunakan yaitu kuesioner sedangkan teknik analisa data yaitu multifariat, dengan besar Sample sebanyak 27 orang. Hasil penelitian terdapat hubungan yang signifikan antara relaksasi Nafas Dalam terhadap penurunan Intensitasn Nyeri Haid pada Siswi Ramaja Putri di MAN Insan Cendekia Halmahera Barat yaitu dengan melihat hasil hitung statistic nilai $\mathrm{P}$ value $=0.0001$ yang berarti $\alpha<0.05$. Simpulan: teknik relaksasi Nafas dalam memberikan pengaruh siginifikan terhadap intensitas nyeri haid pada Remaja Putri di MAN Insan Cendekia Halmahera Barat.

\section{Kata Kunci : Intensitas Nyeri Haid, Teknik Relaksasi Nafas Dalam}

\section{PENDAHULUAN}

Dismenorhoe merupakan suatu gejala rasa sakit atau rasa tidak enak diperut bagian bawah pada masa menstruasi sampai dapat mengganggu aktivitas sehari-hari yang dapat mengganggu aktifitas sehari-hari yang paling sering ditemukan pada wanita dan reproduktif. Dismenore adalah keluhan yang paling sering menyebabkan wanita muda pergi ke dokter untuk konsultasi dan mendapatkan pengobatan (Winkjosastro, 2007). Prevalensi dismenore dalam beberapa penelitian menunjukkan frekuensi yang cukup tinggi. Dalam suatu systemic review World Health Organization (WHO), ratarata insiden terjadinya dismenore pada wanita muda antara 16,8-8\%.

Sebanyak $90 \%$ dari remaja wanita diseluruh dunia mengalami masalah saat haid dan lebih dari $50 \%$ dari wanita haid mengalami dismenorhoe primer dengan 10$20 \%$ dari mereka mengalami gejala yang cukup parah. Prevelensi dismenore di Indoensia sebesar 64,25\% yang terdiri dari 54,89 dismenore primer dan 9,36\% dismenore sekunder. Dismenore primer dialami dialami oleh 60-75\% remaja, dengan tiga perempat dari jumlah remaja tersebut mengalami nyeri ringan sampai berat. Disurabaya didapatkan sebesar 1,07-1.31\% dari jumlah kunjungan ke bagian kebidanan adalah penderita dismenore.

Di Indonesia Dismenore juga merupakan keluhan yang sering ditemukan pada wanita usia muda. Menurut Ernawati dkk (2010), dalsm suatu penelitian pada 50 orang Mahasiswi disemarang ditemukan kejadian dismenore ringan sebanyak $18 \%$, dismenore sedang $60 \%$ dan dismenore berat $20 \%$. Rasa ketidaknyamanan dari dismenore akan mempengaruhi secara emosional dan fisik secara individu sehingga diperlukannya tindakan ataupun pengobatan untuk mengatsi rasa sakit saat menstruasi ini. Dismenore sering menjadi alasan seorang 
mahasiswa untuk tidak masuk mengikuti perkuliahan sehingga akan mengganggu prestasi belajar. Bagi wanita yang bekerja, dismenore akan sangat mengganggu aktifitas sehingga akan dapat menurunkan produktivitas dan kualitas kerja.

Di Amerika serikat, dalam suatu data review ditemukan bahwa 600 juta jam kerja hilang akibat dari dismenore yang mengakibatkan suatu kerugikan secara ekonomi sampai milliard dolar Amerika (Zhu X, dkk. 2009). Menurut Singh (2008), pada sebuah penelitian di India terhadap terhadap mahasiswa kedokteran ditemukan $31,67 \%$ mengalami dismenore dan 8,69\% diantranya tidak dapat mengikuti perkuliahan akibat gangguan menstruasi ini. Sedangkan di Indonesia, dalam suatu penelitian yang dilakukan pada 100 wanita antara usia 15-30 tahun didapati $71 \%$ mengalami dismenore dimana $5,6 \%$ tidak masuk sekolah atau tidak bekerja dan 59.2\% mengalami kemunduran produktifitas kerja akibat dismenore (Novia, 20016). Obatobatan penghilang rasa sakit sering kali digunakan oleh wanita yang mengalami dismenore atau nyeri haid. Terkadang obatobatan ini dibeli tanpa adanya resep dari dokter. Sehingga dalam penggunaanya sering kali mendatangkan efek samping yang tidak diinginkan jika penggunaan obatobatan ini tidak sesuai dengan dosis dan indikasi yang tepat. Obat-obatan yang sering digunakan adalah obat Anti Inflamasi Non steroid, seperti asam mefenamat, ibu profen, piroxicam dan lain-lain. Dalam sebuah data review, dikatakan bahwa sekitar 20-25\% penggunaan Obat Anti Inflamasi Non Steroid untuk mengatasi dismenore dapat gagal ditambah lagi dengan adanya kemungkin mengalami gangguan gastrointestinal pada pemakaian obat ini (Zhu X dkk. 2009).

Bidan sebagian tenaga kesehatan dapat mengatasi nyeri haid baik secara mandiri maupun secara kolaboratif dengan menggunakan dua pendekatan berupa pendekatan farmakologis dan non farmakologis. Pendekatan non farmakologis merupakan pendekatan kolaborasi antara dokter dengan perawatn yang menekankan pada pemberian obat mampu menghilangkan sensasi nyeri. Sedangkan pendekatan non farmakologis merupakan pendekatan untuk menghilangkan nyeri dengan menggunakan teknik manajemen nyeri dengan menggunakan teknik manajemen nyeri meliputi stimulasi dan massage kutaneus, terapi es dan panas, stimulasi syaraf elektris transkutan, distraksi, imajinasi termbimbing, 
hypnosis dan teknik relaksasi nafas dalam. Teknik relaksasi nafas dalam merupakan intervensi mandiri keperawatan dimana bidan juga mengajarkan kepada pasien bagaimana cara melakukan nafas dalam, nafas lambat (menahan inspirasi secara maksimal) dan bagaimana memghembuskan nafas dalam secara perlahan untuk merilekskan ketegangan otot yang menunjang nyeri.

Upaya yang telah dilakukan oleh pasien atau remaja yang mengalami dismenore yaitu pemberian obat analgesic untuk menurunkan nyeri. Namun, walaupun upaya ini telah dilakukan ternyata masih ada pasien yang mengeluhkan nyeri. Mungkin salah satu penyebabnya karena dalam penatalaksanaanya nyeri, pasien atau remaja putrid yang mengalami dismenore lebih menekankan pada pemberian analgesic dan belum melakukan intervensi medis seperti pembelajaran teknik relaksasi nafas dalam. Akibatnya, ketika efek analgesic menurun atau hilang maka sensasi nyero akan dirasakan, walaupun tingkat keefektifannya masih belum ada angka pasti, karena hal inilah maka perlu dilakukan penelitian lebih lanjut tentang pengaruh teknik relaksasi nafas dalam terhadap intensitas nyeri haid (dismenore) pada remaja putrid.

\section{METODE}

Penelitian ini didesain berupa penelitian Pra eskperimen dengan rancangan one group test design adalah dengan mengungkapkan hubungan sebab akibat dengan cara melibatkan suatu kelompok subjek yang diobservasi sebelum dilakukan intervensi, kemudian diobservasi lagi setelah diinterevensi. Penelitian ini bertujuan untuk melihat bagaimana pengaruh teknik relaksasi nafas dalam terhadap nyeri pada remaja putri di MAN Insan Cendekia Halmahera Barat. Penelitian dilaksanakan di sekolah MAN Insan Cendekia Halmahera Barat dan dilaksanakan pada Bulan Oktober Populasi dalam penelitian ini adalah semua Remaja Putri MAN Insan Cendekia Halmahera Barat dengan. Sampel pada penelitian ini adalah semua populasi remaja putri yang mengalami Nyeri Haid (dismenore) di MAN Insan Cendekia Halmahera Barat, yang bersedia menjadi responden yang berjumlah 27 orang. Bentuk penyajian datanya menggunakan table distribusi frekuensi dan presentasi ungtuk data kategori, sedangkan data numerik ditampilkan dari hasil perhitungan mean, median, nilai maksimum-minimum, stnadar deviasi dan CI 95\%. Analisis yang digunakan yaitu univariabel dan bivariabel : 
analisi Univariat untuk melihat distribusi frekunesi variable independen proporsi remaja yang mengalami nyeri haid sedangkan Bivariabel dilakukan untuk menguji hubungan Variabel bebas dan variable terikat dengan Uji statistic dengan Uji t. hasilnya dianalisis berdasarkan kekuatan pengaruh dan resiko prevalnesi dengan tingkat kepercayaan 95\% dan nilai kemaknaan $\alpha=0.05$.

\section{HASIL DAN PEMBAHASAN}

Setelah dilakukan penelitian dengan mengadakan wawancara dan pengisian data ke dalam lembar observasi kepada para siswi MAN IC Halmahera Barat sejumlah 27 orang yang berusia 15-19 tahun dan sesuai dengan kriteria inklusi.
Dari 27 siswi yang mengalami nyeri haid akan mendapatkan intervensi yaitu diberikan teknik relaksasi saat nyeri haid berlangsung. Sebelum diberikan Teknik relaksasi, Siswi yang bersangkutan diamati dan diukur dahulu untuk skala nyeri nya menggunakan Vas (Visual Analog Scale), kemudian diberikan intervensi dengan teknik Relaksasi dafas dalam yang dilakukan selama responden merasa nyaman kemudian diukur kembali skala nyeri haidnya, siswi ada yang mengalami penurunan skala nyeri haid dan ada juga siswi yang sudah tidak memiliki keluhan lagi saat menstruasi.

Berikut ini disajikan tabel hasil penelitian sebagai berikut:

Tabel 1. Karakteristik Reponden Berdasarkan Usia

\begin{tabular}{llllll}
\hline & Mean & Median & SD & Min & Mak \\
\hline Usia & 17.23 & 17 & 0.465 & 15 & 19 \\
\hline
\end{tabular}

Berdasarkan Tabel 1 dapat diketahui bahwa rata-rata usia responden adalah 17 tahun dua bulan, usia minimal responden adalah 15 tahun dan usia maksimal responden adalah 19 tahun.

Tabel 2. Nyeri Haid Sebelum Intervensi

\begin{tabular}{ccc}
\hline SKALA NYERI & FREKUENSI (F) & PRESENTASE (\%) \\
\hline 1 & 0 & 0 \\
\hline 2 & 2 & 7.40 \\
\hline 3 & 25 & 92.59 \\
\hline 4 & 0 & 0 \\
\hline Total & $\mathbf{2 7}$ & $\mathbf{1 0 0}$ \\
\hline
\end{tabular}


Berdasarkan Tabel 2 dapat diketahui bahwa skala nyeri haid yang dialami siswi sebelum diberikan intervensi sebagian besar berada pada angka 3 atau termasuk kategori nyeri sedang yaitu sebanyak 25 responden $(92.59 \%)$.

Tabel 3. Nyeri Haid Setelah Intervensi

\begin{tabular}{ccc}
\hline SKALA NYERI & FREKUENSI (F) & PRESENTASE (\%) \\
\hline 1 & 8 & 29,63 \\
\hline 2 & 13 & 48,14 \\
\hline 3 & 6 & 22,22 \\
\hline 4 & 0 & 0 \\
\hline Total & & $\mathbf{1 0 0}$ \\
\hline
\end{tabular}

Berdasarkan Tabel 3 dapat diketahui bahwa skala nyeri haid yang dialami siswi setelah diberikan intervensi teknik Relaksasi Nafas
Dalam sebagian besar berada pada angka 2 atau termasuk kategori nyeri sedang yaitu sebanyak 13 responden $(48,14 \%)$.

Tabel 4. Pengaruh Teknik Relaksasi Nafas Dalam Terhadap Penurunan Intensitas Nyeri Haid

\begin{tabular}{lccc}
\hline Skala Nyeri & Mean & Standar Deviasi & P Value \\
\hline Preintervensi & 5,75 & 1,878 & \multirow{2}{*}{0.0001} \\
\cline { 1 - 2 } Post Intervensi & 5,23 & 1,888 & \\
\hline
\end{tabular}

Keterangan: *Uji T berpasangan 
Berdasarkan Tabel 4 dapat disimpulkan bahwa dari hasil perhitungan dengan menggunakan Uji $T$ berpasangan yaitu dengan membandingkan skala nyeri haid yang dialami responden sebelum diberikan intervensi dan setelah diberikan intervensi menunjukkan bahwa ada pengaruh pemberian teknik relaksasi nafas dalam terhadap penurunan nyeri haid yang ditunjukkan dengan nilai $\mathrm{P}$ value $=0,0001$ yang berati $<\alpha 0,05$. Hal ini juga dapat dilihat dari perbedaan rerata skala nyeri haid sebelum dan sesudah pemberian intervensi hal ini berarti bahwa ada pengaruh pemberian Teknik Relaksasi Nafas dalam terhadap penurunan nyeri haid pada siswi.

\section{Karakteristik usia responden}

Berdasarkan pada hasil penelitian yang telah didapatkan rata-rata usia responden adalah 17,23 tahun dengan usia minimum 15 tahun dan maximum 19 tahun. Hal ini sesuai dengan penelitian sebelumnya yaitu penelitian yang dilakukan oleh Novia dan Puspitasari (2008) tentang faktor-faktor yang mempengaruhi kejadian dismenore primer. Penelitian menunjukan bahwa dismenore primer lebih banyak ditemukan pada rentang usia 15-25 tahun dengan persentase $87 \%$ pada jumlah responden 100 orang. Penelitian lainnya oleh Ortiz (2010) menunjukan bahwa rata-rata usia responden yang mengalami dismenore adalah 17-35 tahun. Dismenore primer umumnya dimulai pada 1-3 tahun setelah haid pertama (menarche). Kasus ini bertambah berat beberapa tahun hingga usia 23-27 tahun (Morgan dan Hamilton, 2009).

\section{Skala nyeri dismenore pre dan post}

Pada saat sebelum diberikan intervensi skalanyeri haid sebagian besar responden adalah berada di angka 3 yang berati nyeri sedang yaitu sebanyak 25 responden $(92,59 \%)$. Setelah diberikan intervensi yaitu diberikan interfensi teknik relaksasi nafas dalam kemudian 30 menit kemudian diukur skala nyeri haidnya kembali. Dari hasil pengukuran reponden Sebagian besar responden mengalami penurunan skala nyeri haid menjadi 2 yaitu nyeri ringan sebanyak 13 responden $(48,14 \%)$. Selain itu juga ada peningkatan jumlah responden yang tidak mengalami nyeri haid menjadi 8 responden $(29,63 \%)$. Hasil penelitian juga menunjukkan adanya penurunan rata-rata skala nyeri haid sebelum dan sesudah intervensi sebanyak 2,52 point. Hasil penelitian tersebut didukung oleh Suparmi (2016) tentang pengaruh jahe asam terhadap nyeri dismenore primer yang menunjukan bahwa ada penurunan skala nyeri haid pada siswi setelah diberikan teknik relaksasi nafas dalam selama 2 hari. Hasil penelitian juga didukung oleh penelitian Juliana (2014) yang menunjukkan bahwa ada 
penurunan skala nyeri luka opreasi setelah. Dilakukan teknik relaksasi Nafas mampu mengurangi nyeri responden sehingga mereka dapat melanjutkan aktivitas seharihari.

\section{Pengaruh minuman rempah jahe asam asam Terhadap Penurunan \\ Nyeri Haid Primer}

Berdasarkan hasil uji statistik Uji $T$ berpasangan didapatkan hasil bahwa nilai $\mathrm{P}$ value adalah 0,0001 yang berati $<\alpha \quad 0,05$ yang menyimpulkan bahwa Ha diterima dan Ho ditolak. Hal ini menunjukan bahwa ada pengaruh teknik relaksasi nafas dalam terhadap penurunan nyeri haid pada siswi. Hasil peneliian juga menunjukkan adanya penurunan rata-rata skala nyeri haid sebelum dan sesudah intervensi sebanyak 2,52 point.

Nyeri Haid terjadi akibat endometrium mengalami peningkatan prostaglandin dalam jumlah tinggi. Di bawah pengaruh progesteron selama fase luteal haid, endometrium yang mengandung prostaglandin meningkat mencapai tingkat maksimum pada awalan haid. Prostaglandin menyebabkan kontraksi myometrium yang kuat dan mampu menyempitkan pembuluh darah mengakibatkan iskemia, disintegrasi endometrium dan nyeri (Morgan \& Hamilton, 2009).
Prostaglandin F2 alfa adalah suatu perangsang kuat kontraksi otot polos myometrium dan konstriksi pembuluh darah uterus. Hal ini memperparah hipoksia uterus yang secara normal terjadi pada haid sehingga timbul nyeri berat (Corwin, 2009). Selain itu, kejadian Nyeri Haid primer juga dapat dipicu oleh faktor psikogenik yaitu stress emosional dan ketegangan, kurang vitamin, atau rendahnya kadar gula (Widyastuti, 2009).

Nyeri Haid muncul berupa serangan ringan, kram pada bagian tengah, bersifat spasmodik yang dapat menyebar ke punggung atau paha bagian dalam. Umumnya ketidaknyamanan muncul 1-2 hari sebelum haid. Namun nyeri paling hebat muncul pada hari pertama haid. Nyeri Haid kerap disertai efek seperti muntah, diare, sakit kepala, nyeri kaki, dan sinkop (Morgan \& Hamilton, 2009).

Pada penelitian ini responden diberikan intervensi Teknik Relaksasi Nafas Dalam pada saat mereka mengalami dismenorhea primer. Saat responden mengalami nyeri haid primer kemudian diukur skala nyeri haidnya, kemudian setelah itu diukur kembali skala nyeri haidnya setelah 30 menit perlakuan. Hasil dari intervensi ini adalah sebagian besar responden mengalami penurunan nyeri haid. prostaglandin. Penelitian menunjukan bahwa Tekanik Relaksasi memiliki efektivitas yang sama 
dengan asam mefenamat dan ibuprofen dalam mengurangi rasa nyeri pada Nyeri Haid primer. Selain itu tidak ditemukan efek samping yang parah dari Teknik Relaksasi Nafas dalam (Corwin, 2009).

Menurut Smeltzer\& Bare (2002) tujuan teknik relaksasi napas dalam adalah untuk meningkatkan ventilasi alveoli, memelihara pertukaran gas, mencegah atelektasi paru, meningkatkan efesiensi batuk, mengurangi stress baik stress fisik maupun emosional yaitu menurunkan intensitas nyeri dan menurunkan kecemasan.

Teknik relaksasi nafas dalam dipercaya dapat menurunkan intensitas nyeri melalui mekanisme yaitu (Smeltzer\& Bare, 2002) :

1. Dengan merelaksasikan otot-otot skelet yang mengalami spasme yang disebabkan oleh peningkatan prostaglandin sehingga terjadi vasodilatasi pembuluh darah dan akan meningkatkan aliran darah ke daerah yang mengalami spasme dan iskemic.

2. Teknik relaksasi nafas dalam dipercayai mampu merangsang tubuh untuk melepaskan opoiod endogen yaitu endorphin dan enkefalin

3. Mudah dilakukan dan tidak memerlukan alat Relaksasi melibatkan system otot dan respirasi dan tidak membutuhkan alat lain sehingga mudah dilakukan kapan saja atau sewaktu-waktu.

\section{SIMPULAN}

Hasil penelitian menunjukkan terdapat hubungan yang signifikan antara relaksasi Nafas Dalam terhadap penurunan
Intensitasn Nyeri Haid pada Siswi Ramaja Putri di MAN Insan Cendekia Halmahera Barat yaitu dengan melihat hasil hitung statistic nilai $\mathrm{P}$ value $=0.0001$ yang berarti $\alpha<0.05$.

\section{UCAPAN TERIMA KASIH}

Program Studi Diploma IV Kebidanan Politeknik Kesehatan Kementerian Kesehatan Ternate

\section{DAFTAR RUJUKAN}

Annathayakeisha. (2009). Nyeri Haid. Diakses tanggal 18 Februari 2018. http://klikharry.files.wordpress.co./200 7/02/1.doc+endorphin+dalam+tubuh.

Anonim. (2009). Nyeri Haid. Diakses tanggal $01 \quad$ Maret 2018. http://www.dechacare.com/penyebabnyeri-saat-haid-i323.html.

Anurogo, Ditto. (2011). Nyeri Haid, Yogyakarta: Penerbit Andi.

Gan, G., Sulistia. (2007). Farmakologi Dan Terapi Edisi 5. Jakarta : Fakultas Kedokteran UI.

Hacker F Nevellie. (2008). Esensial Obstetric Dan Ginekologi Edisi 2. Jakarta : EGC.

Hardjosaputra, S.L.P., Purwanto, L., Kemalasari, T., Kunardi, L., Indriyantoro, Indriyani, N., (2008). Data Obat Di Indonesia Edisi 11. Jakarta : PT Muliapurna Jayaterbit. 
Kalalo Ribla, dkk. (2017). Pengaruh Teknik Relaksasi nafas dalam terhadap respon nyeri pada Ibu Inpartu Kala I Faae Aktif di Puskesma Bahu Kota Manado, e-journal keperawatan (e-Kp) Volume 5 Nomor I Mei 2017. Diakses tanggal 2 Februari 2018. 